\title{
VELOCIDADE/ACELERAÇÃO TEMPORAL E INFECÇÕES EMERGENTES: EPIDEMIOLOGIA E TEMPO SOCIAL
}

\author{
SPEED/TEMPORAL ACCELERATION AND \\ EMERGING INFECTIONS: EPIDEMIOLOGY \\ AND SOCIAL TIME
}

Gil Sevalho*

\begin{abstract}
SEVALHO, G.: 'Speed/temporal and emerging infections diseases: epidemiology and social time'. História, Ciências, Saúde - Manguinbos, III (2):217-236 Jul.-Oct. 1996.

In an examination of epidemiology and social time, this paper argues that the time perspective should be an important consideration within epidemiology. 'Time' is an element to which this field devotes little theoretical attention, although it is present as a part of epidemiology's main concepts. Drawing from bistory and geography, the text offers bistorical notes on social time as imposed by globalized capitalism and its implications regarding the bealth of buman populations. The speed/temporal acceleration of contemporary societies and their relationships to emerging infections is discussed. Lastly, the paper presents some critical considerations regarding the concepts of social time and of a probable epidemiological time.
\end{abstract}

KEYWORDS: cpidemiology, social time, emerging infections diseases.

\section{Introdução}

*Doutorando da Escola Nacional de Saúde Púlblica/Fiocruz.

Rua Campo Belo, 312/ 1001

Belo Horizonte, Minas Gerais $30330-330$
Nossas vidas estão inexoravelmente marcadas pelo tempo. Embora raramente fixemos a atenção nisto, haverá sempre um tempo marcando nossa existência, nossas emoções, sucessos e desilusões. Nossas lembranças, onde habitam as imagens que temos das pessoas e do mundo, são forjadas pelos sentidos que temos do tempo. Nosso pretenso conhecimento da realidade, a ciência, o juízo que fazemos das 'coisas, nossas crenças e valores, armazenados em nossas memórias, e nossos projetos e sonhos, são construídos sobre as representações que fazemos do tempo.

Ao se referir ao tempo e ao espaço, Harvey (1993, p. 187) aponta-os como "categorias básicas da existência humana". No entanto, para o autor, raramente discutimos o seu sentido, "tendemos 
a tê-los por certos e lhes damos atribuições do senso comum ou auto-evidentes. Registramos a passagem do tempo em segundos, minutos, horas, dias, meses, anos, décadas, séculos e eras, como se tudo tivesse o seu lugar numa única escala temporal objetiva". $\hat{E}$ assim, complementa o autor, que organizamos nossas rotinas diárias em torno de um senso comum do tempo.

No entanto, estas rotinas diárias são povoadas de sentidos diversos de tempo, onde se misturam movimentos repetidos $\mathrm{e}$ inéditos, inconscientes ou não, recordaçôes, hábitos e desejos. Mesmo porque nossos afazeres e compromissos estão diretamente relacionados à forma como se movimenta a sociedade, às maneiras como se estabelecem as relações de produção e, historicamente, se constrói a cultura. Costumes, ritos, tradições imbricam-se no tempo com o trabalho, o lazer e o exercício da sobrevivência de tal modo a conformar diferentes tempos sociais.

Discutir sobre estes tempos sociais em sua relação com o adoecer humano coletivo é o objetivo central deste artigo. Mais especificamente serão abordadas as relações entre as chamadas infecções emergentes e o tempo do capitalismo globalizado, o que será feito com aportes principalmente da geografia e da história. Num sentido mais amplo, a perspectiva é envolver o ponto de vista do tempo na reflexão epidemiológica. O tempo é elemento central de alguns dos conceitos fundamentais da disciplina, como os de endemia e epidemia, mas não tem sido objeto de discussões específicas aprofundadas.

Formalmente, o texto, após esta introdução, trabalha uma construção histórica da aceleração temporal que marca fundamentalmente a contemporaneidade. Construção, ou reconstrução, esta que prossegue com uma discussão sobre o tempo do capitalismo globalizado. Uma terceira parte do texto é dedicada à apresentação epidemiológica da questão das infecções emergentes. Numa quarta parte são esclarecidas as relações da aceleração temporal do capitalismo globalizado com as infecçôes emergentes. $\mathrm{E}$, posteriormente, são discutidas algumas questões de ordem conceitual acerca do tempo social e do tempo da epidemiologia, enquanto área do conhecimento. Uma discussão que é finalizada com algumas pontuações críticas sobre a adequação do tempo epidemiológico para lidar com as dimensões históricas e sociais do adoecer humano coletivo.

\section{Notas históricas sobre um tempo social da modernidade}

Nesta discussão, que enfoca a epidemiologia e a globalização do capital, falar de tempo social significa falar de velocidade e aceleração, de um tempo que parece se sobrepor aos demais, dominando um sistema desigual de influências, preponderantemente de 'mão única'. 
Para pensá-lo, é interessante considerar a opinião de Santos (1994, p. 42), quando explicita que "tempo, espaço e mundo são realidades históricas, devem ser intelectualmente reconstruídas em termos de sistema, isto é, como mutuamente conversíveis, se a nossa preocupação epistemológica é totalizadora".

Em se tratando de uma história deste tempo social que vivemos e que passa velozmente por nós, é importante recorrer a LeroiGourhan (1987, p. 124), quando assinala que a partir do paleolítico superior, provavelmente, se deu "uma domesticação" do tempo e do espaço feita através de "dispositivos simbólicos", dos quais "a linguagem é o instrumento principal". Domesticação esta que se traduz na "passagem da ritmicidade natural das estações do ano, dos dias, das distâncias da marcha, para uma ritmicidade regularmente condicionada pela rede de símbolos, calendários, horários, métricos ...", construída e controlada pelo ser humano.

No entender de Le Goff (1979, pp. 43-53), quando do declínio da ordem feudal e do surgimento das cidades e dos mercadores, o tempo, que era marcado pelos chamados dos sinos para os ofícios religiosos, passou ao domínio dos relógios mecânicos que medem mais exatamente o envolvimento com as "tarefas profanas e laicas", os compromissos de negócios. Ao apontar para "um novo conceito de Idade Média", o autor aborda "o tempo da igreja e o tempo do mercador", descrevendo, por exemplo, como certos pensadores cristãos, entre os séculos XII e XIV, se insurgiram contra a perspectiva da "usura" embutida na prática do crédito pelos mercadores. O pecado da usura residiria na utilização do tempo, algo que pertenceria a Deus e não aos mercadores, para a consecução dos seus lucros.

Como explica Le Goff (idem, p. 53), "o mercador descobre o preço do tempo na mesma altura em que explora o espaço, pois para ele a duração essencial é a de um trajeto", para o qual deve se preparar pensando seus negócios e ganhos em relação às estações do ano, às intempéries e cataclismos naturais, entre os quais se inscrevem as pestes e as fomes.

Para Whitrow (1993, p. 128), quando se reporta ao mesmo momento da história, "enquanto o poder se concentrou na posse de terras, o tempo era vivido como abundante ... associado ao ciclo inalterável do solo". Com a transferência de poder para os mercadores e banqueiros e a circulação de dinheiro, "a ênfase deslocou-se para a mobilidade" e "muitas das classes médias não tardaram a perceber que tempo é dinheiro".

A invenção do relógio mecânico, no final do século XIII, acompanhou o desenvolvimento do comércio e uma necessidade cada vez maior de medir com exatidão o tempo. Em substituição aos relógios de sol, que não marcavam as horas da noite, e aos relógios de água, que congelavam no frio dos invernos, foram, 
inicialmente, desenvolvidos grandes engenhos que, embora imprecisos e de alto custo, eram motivo de orgulho para as cidades que os possuíam (Cipolla, 1992). No entanto, um relógio de mesa ou de algibeira, como esclarece Whitrow (1993, pp. 130-1), era uma evocação bem mais presente e visivel do "tempo usado, do tempo gasto, do tempo desperdiçado, do tempo perdido", e engenhos portáteis foram produzidos na Europa a partir do final do século XVI.

A importância do aparecimento do relógio, em relação à ordem simbólica das coisas, pode ser avaliada pela sua utilização enquanto elemento metafórico fundamental para a construção filosófica do mecanicismo no Renascimento. Para Whitrow (idem, p. 145), o relógio mecânico foi "o instrumento protótipo ... da concepção mecânica do universo". Descartes, por exemplo, comparou um homem doente a "um relógio mal fabricado" e um homem saudável a "um relógio bem-feito" (Capra, 1988, p. 57).

O relógio mecânico e o advento do racionalismo científico moderno foram acompanhados de mudanças nas concepçôes de tempo. O tempo da Idade Média, "linear", que "tem um sentido, uma direção, tende para Deus" e é "condição necessária e natural de todo o ato divino" (Le Goff, 1979, pp. 45 e 47), e o tempo alimentado pelas inspirações "passadistas" que acompanharam o resgate do paganismo da Antiguidade no declínio do período medieval (Whitrow, 1993, p. 153), perderam sua força enquanto representações sociais hegemônicas. A partir dos anos 1600 e principalmente do século XVIII, o Século das Luzes, perspectivas mais favoráveis em relação a um processo de evolução impregnaram as representações de tempo.

Assim é que o século XIX, no bojo do desenvolvimento científico e tecnológico, à época da afirmação da Revolução Industrial, representou, na interpretação de Hobsbawm (1979, p. 308), "a descoberta da história como um processo de evolução lógica, e não simplesmente uma sucessão cronológica de acontecimentos". O positivismo de Augusto Comte, a teoria da evolução das espécies de Charles Darwin, inspirada nas idéias de Thomas Malthus contidas no Essay on population, e a economia política de Karl Marx surgiram dessa forma de pensar as coisas.

Nesta época, para Hobsbawm (1979, pp. 242, 255-6), "embora, em termos puramente quantitativos, a religião continuasse muito forte e ... ficaria ainda mais forte, ela não era mais dominante, mas recessiva". Impregnados por uma "ideologia leiga ou secular", profundamente racionalistas, tanto os liberais burgueses quanto os revolucionários proletários de então "acreditavam que a sociedade humana e o homem individualmente poderiam ser aperfeiçoados pela mesma aplicação da razão, e que estavam destinados a seu aperfeiçoamento na história". É possível admitir, 
então, que mesmo entre os miseráveis já socialmente classificados que se acumulavam na imundície da urbanização desqualificada que acompanhou o processo de industrialização do século XIX, na Europa, houvesse uma certa perspectiva de evolução. Algo que suportou os seus projetos revolucionários, inspirados nos ideais da recente Revolução Francesa, que culminaram com os movimentos revolucionários europeus de 1848.

Este sentimento de revolta também contaminou as artes da época e fomentou seu florescimento. Hobsbawm (idem, p. 278), ao se referir a isso, aponta que, "se fôssemos resumir as relações entre o artista e a sociedade nesta época em uma só frase, poderíamos dizer que a Revolução Francesa inspirava-o com seu exemplo, que a Revolução Industrial com seu horror, enquanto a sociedade burguesa, que surgiu de ambas, transformava sua própria experiência e estilos de criação".

A era industrial e a reprodução do capital trouxeram também para o ser humano moderno uma necessidade incessante de aceleração da produção e do consumo.

\section{O tempo da globalização}

Braudel (1987) identifica três componentes da realidade econômica que devem ser analisados para a compreensão do capitalismo atual. A vida material é a economia informal, onde se estabelecem as trocas familiares e ao nível da aldeia, onde situam-se os hábitos e costumes, a luta cotidiana dos seres humanos por sua sobrevivência. A vida econômica, da economia de mercado governada pela concorrência, que liga as cidades e os burgos pelo comércio. E um terceiro nível, o capitalismo, onde está o comércio a distância, internacional, funcionando segundo regras ditadas pelo monopólio e orientado pelo poder e não pela necessidade.

Mas, como explica Reis (1994a), esta divisão da realidade em camadas, promovida por Braudel, também significa tempos diferenciados. Assim, a vida material é a do tempo longo, da profundidade quase inercial da história, das estruturas, das permanências, onde se abrigam as ações e os movimentos repetitivos, na maior parte inconscientes, da luta cotidiana do ser humano anônimo com o meio exterior. A vida econômica é a do tempo médio, das conjunturas, dos ciclos que ligam a longa cluração ao tempo curto. E, finalmente, o capitalismo é o tempo curto, onde se localizam os eventos na superfície da história. É este tempo do capitalismo, o tempo do mundo, a aceleração, que pretende sempre penetrar em todos os interiores, dominar os ritmos e tempos destes interiores.

Até o século XVIII, segundo Braudel (1987), o mercado e o capitalismo eram minoritários, e a grande aceleração temporal que 
os acompanha só se iniciou de fato no século XIX. No entanto, o autor vê o surgimento de processos, operações comerciais e monetárias, que estão melhor situados no capitalismo do que no mercado, desde o século XV. Para designar estes processos, diz Braudel (1987, p. 42), "a palavra que acode mais espontaneamente ao espírito é bem capitalismo. Irritados, expulsamô-la pela porta e ela volta em seguida a entrar pela janela." Assim, o termo prevalece diante da inadequação histórica de outros para substituí-lo.

$\mathrm{Na}$ verdade, esta visualização de vestígios ancestrais do capitalismo é uma ilustração que deixa perceber a aplicação da dialética da duração de Braudel (1992), um tempo histórico que relaciona estrutura, conjuntura e evento. Um tempo que une os tempos longo, médio e curto, porém distinguindo-os na perspectiva fundamental do tempo longo, da longa duração. Como afirma Braudel (1987, p. 54), "tudo é transportado nas costas enormes da vida material". O evento, a mudança, no caso o capitalismo, deve ser percebido nesta dialética, um tempo caracteristicamente não-determinista, irreversível e coletivo.

Para Braudel (1987, pp. 68-9, 77), as condições de uma "economia-mundo", bases do capitalismo contemporâneo, seriam a ocupação de um espaço geográfico determinado, com limites variáveis, e a aceitação de um pólo, mantenedor de uma "reciprocidade de perspectivas". Seria, assim, conformada uma situação onde o centro depende do abastecimento da periferia $e$ esta depende das necessidades deste centro, que lhe impõe suas leis de maneira a estabelecer "zonas sucessivas" de influência. Dessa maneira, as desigualdades gradativas entre o centro e a periferia alimentam o sistema.

Como explica Santos (1994, p. 17), "a história do homem sobre a Terra é a história de uma rotura progressiva entre o homem e o entorno". Os mecanismos de sobrevivência, o desenvolvimento de técnicas e ferramentas e o trabalho estabelecem espaços e tempos próprios de cada realidade, de cada cenário.

A sociedade e o espaço se transformam, "e em cada uma dessas transformações está envolvida uma atribuição de uma temporalidade particular que é a que vive a sociedade particular num dado momento" (Nicolas, -1994, p. 85). A história, a cultura e a organização da produção, enfim, delimitam seus tempos peculiares, espaços e mundos.

Apoiado nas técnicas e ambientado nas cidades, o capitalismo evoluiu desde cerca de cinco séculos, instituiu a Revolução Industrial, e uniu o mundo atual sob a égide do consumo. A população mundial aumentou aceleradamente, os espaços se transformaram rapidamente, a urbanização cresceu e quase se tornou completa, e os meios de comunicação e transporte foram aperfeiçoados de tal forma a promover uma espécie de superposição 
dos espaços e dos tempos com sua velocidade de deslocamento físico e imaginário cada vez maior.

O comércio e a expectativa do lucro sempre necessitaram de maior mobilidade social e maior velocidade de deslocamento, seja físico ou imaginário. O espaço e o tempo foram 'colonizados' no sentido de suprir estas necessidades. Mesmo porque, quando o tempo é dinheiro, a duração é um obstáculo à circulação de mercadorias que deve ser vencido.

A perspectiva da globalização está na "possibilidade de tudo conhecer e utilizar em escala planetária" (Santos, 1988, p. 12). O capitalismo transnacionalizado perpassa as fronteiras dos espaços e dos tempos locais. O tempo veloz do capitalismo mundializado é um tempo que abrange os demais tempos sociais. Não necessariamente os dissolve, mas os incorpora perifericamente, os utiliza segundo seus próprios interesses, e lhes impõe ritmos, permanências e mudanças.

No sistema globalizado, "as técnicas são utilizadas em toda a parte sem consideração pelos sistemas locais ... superpostas a realidades econômicas e sociais diferentes" (idem, p. 35). A convivência do tempo da globalização com os outros tempos, os tempos locais, é, portanto, possível e mesmo necessária, mas sempre subordinando-os a uma ordem maior, a da aceleração. Assim é que o tempo longo e circular, lento, das sociedades tradicionais, que está associado a um modelo tecnológico simples (Nicolas, 1994), pode muito bem sobreviver e

As coisas orientam-se por uma organização manejada a distância pelas redes de telecomunicações e transportes que sustentam a transnacionalidade do capital, e os "novos nexos" e "também desejos e necessidades" se fazem "segundo parâmetros estranhos às necessidades íntimas" dos grupos locais (Santos, 1994, p. 18), resultando disto uma fragmentação dos ritmos locais. Há um 'imperialismo' do tempo da globalização sobre os outros tempos.

Ao nível do espaço, o mundo assim conformado é um mundo em desgaste. Se antes o ser humano retirava do entorno o necessário para sua sobrevivência, cercado por crenças e rituais que o incluíam na natureza, agora há um movimento de unificação movido pelo capitalismo e pela ciência que o tem como dono desta natureza, não mais como seu partícipe. O cristianismo ocidental impôs à cultura a idéia de "domínio sobre os peixes do mar e os pássaros do céu, e sobre todas as coisas vivas que se movam sobre a face da Terra" (Crosby, 1993, p. 29), e a ciência moderna conferiu ao ser humano o poder da manipulação exaustiva da natureza. "Patrão da natureza", o ser humano perdeu a medida do uso do entorno (Santos, 1988, p. 44).

A globalização é também "universalização" (Santos, 1988, p. 14). Universalização da produção, das trocas, do mercado de tra- 
balho, do consumo e do gosto pelo consumo, do espaço, do tempo. Mas é também fragmentação das identidades individuais e grupais, das relações humanas com o espaço e o tempo, alienação do trabalho e exclusão social.

Novos padrões de consumo são impostos a cada momento. "O dinamismo inato da economia moderna e da cultura que nasce dessa economia aniquila tudo aquilo que cria ... a fim de criar mais, de continuar infindavelmente criando o mundo de outra forma" (Berman, 1988, p. 273).

Como esclarece Braudel (1987, p. 18), "tudo é técnica desde sempre", e o tempo social da globalização é, por excelência, uma velocidade cada vez maior de industrialização, uma aceleração da produção e do consumo de tecnologias novas. E é este também o tempo das chamadas infecções emergentes.

\section{Os "fatores responsáveis" pelas infecções emergentes}

Apesar do desenvolvimento da microbiologia desde o último terço do século XIX, com os trabalhos de Robert Koch e Louis Pasteur, e dos progressos da medicina, as doenças infecciosas continuam a afligir a humanidade.

Recentemente, na década de 1980, na trágica presença da Aids, e sob a ameaça de patógenos poderosos como o vírus Ebola ou o Hantavírus, a epidemiologia voltou mais efetivamente sua atenção para as chamadas infecções emergentes.

Para Morse (1995, p. 12) as "infecções emergentes" podem ser definidas como aquelas que só recentemente surgiram ou que já existiam, mas "rapidamente aumentam sua incidência ou extensão geográfica". O autor sugere que, de modo "operacional", estas infecções podem ser vistas como um "processo de duas fases: 1) introdução de um agente infeccioso em uma nova população de hospedeiros (se o patógeno é originado do meio, possivelmente em outras espécies, ou como uma variante de uma infecção humana já existente), seguido de 2) estabelecimento e disseminação adicional na nova população de hospedeiros".

Morse afirma que, "seja qual for sua origem, a infecção 'emerge' quando atinge uma nova população".

A existência de vários fatores de ordem ecológica e demográfica, como alterações climáticas e migrações, o desenvolvimento dos transportes, a intensificação do comércio, a industrialização e a produção cada vez maior de tecnologias favorecem o surgimento e a transmissão das doenças infecciosas (Lederberg et al., 1992; Morse, 1995). No entender de Morse (idem, p. 11), a ocorrência destes fatores, associada à interrupção ou deficiência de serviços básicos de saúde pública e à "contínua evolução da variação viral e microbiana pela resistência às drogas, sugere que as infecções continuarão a emergir". 
Para o referido autor, os fatores envolvidos na ocorrência das infecções emergentes podem ser encaixados em seis tipos principais: "mudanças ecológicas e desenvolvimento da agricultura", "mudanças demográficas e de comportamento", "viagens internacionais e comércio", "tecnologia e indústria", "mudança e adaptação microbiana" e "interrupção de ações de saúde pública e deficiências na infra-estrutura de serviços sanitários".

As mudanças ecológicas e o desenvolvimento da agricultura, diz Morse (ibidem, p. 15), estão muito freqüentemente ligados ao surgimento de doenças desconhecidas de "introdução zoonótica". Modificações climáticas, alterações nos cursos dos rios e nas correntes marinhas, ao lado das transformações do espaço provocadas pelo desenvolvimento das práticas agrícolas, fatores na maioria das vezes provocados pelos seres humanos, são responsáveis pelo surgimento e expansão das doenças infecciosas.

De outra forma, a maior facilidade de deslocamento físico de pessoas e mercadorias por automóvel, navio ou avião, conseqüência em senso direto da expansão do comércio, propaga as doenças infecciosas. As mudanças demográficas, as migrações e a intensa urbanização atual às quais os seres humanos foram forçados ou atraídos, favorecidas pelo aperfeiçoamento das vias e meios de transporte, têm propiciado o avanço destas doenças. E quanto à questão do comportamento, na perspectiva de Morse (ibidem), sua importância no contexto da Aids, por exemplo, é evidente, no que diz respeito ao uso de drogas intravenosas ou às práticas sexuais.

No que Morse (ibidem, p. 18) classifica como "tecnologia e indústria", contaminações de alimentos no processamento industrial, de hemoderivados utilizados na prática clínica e de equipamentos também de uso médico têm ocasionado a emergência de infecções. Epidemias de intoxicações por produtos alimentícios têm ocorrido e aquelas de infecção pelo vírus Ebola, por exemplo, se propagaram dentro de hospitais, para pessoal médico e outros pacientes, através de contato e/ou uso de equipamento contaminado.

Os patógenos, por sua vez, têm adquirido resistência de outros micróbios, inclusive não patogênicos, ou pressionados pela presença constante de drogas antimicrobianas no meio ambiente. Em raras ocasiões, como explica Morse (ibidem, p. 19), talvez mais em bactérias que em vírus, estas mutações podem originar "novas expressões de doenças", como nos casos da febre purpúrica brasileira, que é causada por uma variante clonal do Haemophilus influenza, e possivelmente da fascí́te necrosante, causada pelo grupo A de Streptococcus, que a mídia apelidou de 'bactéria assassina'. Além disso, quaisquer destes fatores podem intercorrer, 
como admite o mesmo autor, com o colapso ou a deficiência das ações de saúde pública.

Deve ser anotado que Morse (ibidem, p. 18) menciona a "globalização" quando se refere à possibilidade de veiculação e introdução de agentes patogênicos através do consumo de alimentos industrializados que são comercializados pelo mundo, considerando, diz o autor, que a busca por custos mais baixos do processamento industrial tem aumentado o perigo da contaminação "acidental". Modificações no processamento industrial de rações preparadas com carne de ovelhas podem representar um elo importante na ligação entre o scrapie dos ovinos, a doença da vaca louca dos bovinos e a doença de Creutzfeldt-Jakob dos humanos. Sobre isto deve ser visto ainda que o envolvimento dos príns, partículas protéicas, neste processo mórbido, significa a inquietante existência de agentes infecciosos não-vivos.

\section{Velocidade/aceleração temporal e infecções emergentes}

As relações entre o tempo acelerado da globalização do capital e as infecções emergentes devem se dar em dois níveis. A um nível explícito, expresso na objetividade do deslocamento físico de pessoas e mercadorias e da produção e consumo acelerados de tecnologias, e a um nível implícito, subjetivo, mais profundo, complexo, e menos evidente, onde o tempo veloz e acelerado penetra no imaginário, e, embora imponha às pessoas comportamentos e atitudes que favoreçam o adoecer, esta ligação dificilmente é percebida.

Quanto à relação explícita da aceleração temporal com as infecções emergentes, no contexto objetivo da transnacionalização do capital, é importante observar certos aspectos interessantes no que concerne à transformação do espaço. Uma das ações empreendidas muito comumente pela globalização é a substituição dos espaços locais por outros espaços e tempos que só têm a ver com a transnacionalização, mas são alienígenas com referência às realidades locais, como é o caso dos reflorestamentos. Não é difícil perceber que estas áreas que substituem espaços locais, muitas vezes ocupados por agriculturas de subsistência em países pobres, são estranhas aos locais onde são literalmente plantadas. São estranhas enquanto diversidade biológica, à flora e à fauna locais, estranhas culturalmente e estranhas enquanto atividade econômica, pois só se prestam ao manejo a distância das corporações transnacionais. Deve ser relatado que a doença de Lyme se originou justamente em reflorestamentos, onde cresceram populações de veados e carrapatos (Lederberg et al., 1992).

Em outra perspectiva, ainda ligada à transformação do espaço, a diversificação da produção tecnológica cria verdadeiros nichos 
ecológicos novos que servem de hábitats para novas espécies microbianas. Pode ser apontado aqui o caso da doença dos legionários, cujo agente patogênico, a Legionela pneumophila, habita ductos de modernos sistemas de refrigeração, um espaço até recentemente inexistente.

Ainda em se tratando do nível objetivo das relações entre o tempo da globalização, a aceleração de produção e o consumo de tecnologias, e as infecções emergentes, deve ser referida a utilização desmedida de medicamentos antimicrobianos, que, como já foi dito, promove a resistência bacteriana. A perseguição voraz de lucros por parte da indústria farmacêutica, sob a forma de uma promoção publicitária agressiva dos seus produtos ou através da criação de novos fármacos voltados muito mais para uma ampliação de mercado do que propriamente para uma terapêutica mais eficaz, é fato bem conhecido (Dupuy e Karsenty, 1980; Silverman e Lee, 1983; Cordeiro, 1985; Temporão, 1986; Brudon, 1987). Deve ser lembrado, ainda sobre isto, a resistência dos fabricantes de medicamentos em testar os derivados de sangue mesmo já na presença de evidências da implicação destes produtos na propagação da Aids, na primeira metade da década de 1980. O projeto econômico do complexo médico-industrial é tão agressivo a ponto de patentear genes, vírus e pedaços de bactérias, implantando de forma definitiva o mando humano sobre a natureza, numa perspectiva seguida desde o Renascimento pela ciência moderna.

Hoje, as pesquisas científicas, movidas por tecnologias cada vez mais sofisticadas, penetram mais e mais no interior dos corpos humanos e da Terra em busca dos segredos guardados pela natureza. A ciência manipula intimamente a vida através da engenharia genética, implantando genes humanos em animais, tentando mapear o código genético humano através do Projeto Genoma Humano, numa empreitada de cunho predominantemente biologicista, ou enfiando sondas profundas em regiões geladas atrás do passado geológico e biológico do planeta, retirando bactérias de lugares onde nenhum de nós jamais pisou e de tempos que ninguém viveu. As conseqüências sociais e biológicas destas ações ainda são, por enquanto, domínio apenas de nossa imaginação.

No que concerne à velocidade e à oportunidade cada vez maiores de transporte, a ligação com as infecções emergentes é evidente. Com o trânsito de pessoas e cargas podem ser veiculadas infecções. A importância das viagens aéreas nesta relação é fato bem conhecido. Além do que, há situações só recentemente percebidas relacionando provavelmente os transportes e a emergência de infecções, como a invasão em massa de ecossistemas naturais por organismos marinhos que vencem as 
barreiras oceânicas alojados na água utilizada para lastro de navios (Carlton e Geller, 1993).

Em relação à falibilidade das ações de saúde pública, deve ser considerado que, como lembram Sabroza et al. (1995), estas desde há muito sofrem interrupções e descontinuidades justamente porque são pensadas não na perspectiva de transformações sociais reais, mas como instrumentos de controle social que servem à manutenção da acumulação de capital e das desigualdades.

O tempo veloz de produção e consumo de tecnologias implica ainda o depósito de lixos industriais sobre o espaço da Terra, sejam resíduos do processo de industrialização prejudiciais à saúde humana e ao equilíbrio do meio ou restos de produtos já utilizados que são jogados fora e servem de viveiros para vetores de infecções emergentes, como o que ocorre com o Aedes aegypti, responsável pela transmissão do dengue, que prolifera em pneus e garrafas de plástico velhos que recebem água de chuva.

Abordando exatamente esta poluição moderna, Virilio (1993, p.115) indaga se "ao lado da poluição das substâncias que compõem nosso meio ambiente e a respeito das quais o ecologista nos fala incessantemente, não deveríamos entrever igualmente esta súbita poluição das distâncias e dos períodos de tempo que degrada o espaço de nosso hábitat? ... esta poluição de tamanbo natural que reduz a nada a escala, as dimensões terrestres?"

Para Virilio (Virilio e Lotringer, 1984), se antes o poder se expressava pela conquista dos territórios, pela expansão do espaço, hoje, quando o tempo é dinheiro, se expressa pela conquista do tempo, ou, mais exatamente, pela sua retração cada vez maior, pela velocidade. A questão da velocidade é a preocupação principal do autor, que remete este poder sobre o tempo ao movimento de vetores de transporte físico e imaginário cada vez mais velozes, automóveis e audiovisuais, que têm a sua última expressão no computador eletrônico. Instrumento fundamental para as operações financeiras que suportam a globalização do capital.

Nesse sentido, Virilio (1993, p. 12) sustenta que, no mundo de hoje,

"a organização industrial do tempo compensou insensivelmente o esvaziamento dos territórios rurais. Se no século XIX a atração cidade/campo esvaziou o espaço agrário de sua substância (cultural e social), no final do século XX é a vez do espaço urbano perder sua realidade geopolítica em benefício único de sistemas instantâneos de deportação cuja intensidade tecnológica perturba incessantemente as estruturas sociais: deportação de pessoas no remanejamento da produção, deportação da atenção, do face a face humano, do contato urbano, para a interface homem/ máquina." 
Se já foi discutido o nivel explícito, objetivo, das relações entre o tempo da globalização e as infecções emergentes, valeagora explorar o nível implícito, subjetivo, menos perceptível, destas relações.

Para Virilio (idem, p. 11), os vetores audiovisuais, de transporte imaginário, como as televisões, apresentam o mundo às pessoas engolindo as distâncias geográficas e embutindo o passado e o futuro num presente incessante. "Tempo de uma duração técnica", só comparável à memória dos computadores, "duração que contribui para a instauração de um presente permanente cuja intensidade sem futuro destrói os ritmos de uma sociedade cada vez mais aviltada".

Aprisionado entre "acelerações superpostas", neste tempo sem futuro e sem passado onde um "presente que foge" (Santos, 1994, p. 30) parece dissolver a história, o ser humano tem uma imagem confusa do tempo. Mesmo porque os seus ritmos biológicos e sociais são abalados incessantemente.

Quebras de nossos ritmos circadianos, impostas pela sociedade moderna, podem trazer conseqüências em relação à nossa qualidade de vida. Como é o que acontece com os trabalhadores submetidos ao estresse dos turnos rotativos de trabalho, que perdem progressivamente sua integridade, tanto no que diz respeito ao convívio familiar e social quanto naquilo que se relaciona ao funcionamento orgânico, biológico, dos seus corpos.

A aceleração da modernidade vai progressivamente eliminando os hábitos e rituais que estão mesclados em nosso cotidiano, e se uma das principais funções dos rituais tradicionais é ordenar o tempo tal como afirma Leach (1963), nossa percepção do tempo é cada vez mais confusa no que diz respeito ao sentido histórico.

Esta prisão da aceleração fragmenta intimamente as identidades e para viver o ser humano forja comportamentos libertários. Ao contrário do que ocorre nas sociedades tradicionais, "marcadas por uma relativa indistinção de esferas e domínios" onde "vinga a precedência existencial e valorativa do todo sobre as partes e das relações sobre os elementos", o imaginário moderno vê o sistema social "como um fardo que constrange o valor quase sagrado que os modernos atribuem ao indivíduo e à liberdade" (Salem, 1991, pp. 59-61).

Como explica Salem (1991, p. 60), nas sociedades contemporâneas, "no lugar das identidades relacionais, afirmamse identidades auto-referidas: o sujeito é percebido, e se percebe ... como entidade que antecede qualquer relação social".

Salem (idem, pp. 67-9), principalmente a partir de sua leitura de Dumont (1993), considera esta perspectiva como "individualista" e "igualitária". E, segundo a autora, este "individualismo libertário", que embebe a modernidade desde a década de 1960, advoga o "culto às drogas" como um caminho 
para o autoconhecimento e "elege a sexualidade como sua pedra de toque".

Ao nível subjetivo, o envolvimento desta fragmentação de identidades com a emergência das infecções pode ser considerado no que diz respeito à mudança do espectro epidemiológico da Aids. Esta mudança, com a doença atingindo hoje heterossexuais de ambos os sexos, pode estar relacionada com uma certa mobilidade de identidade mais do que com padrões fixos de comportamento. Nestas circunstâncias, sem que isto signifique qualquer atribuição de culpabilidade, o mesmo indivíduo assume várias identidades sociais em momentos diferentes, e pode, assim, funcionar como uma espécie de comunicação na transmissão da doença entre homossexuais e heterossexuais e usuários e não usuários de drogas injetáveis.

No âmbito da "singularidade do adoecer humano", para usar uma expressão de Castiel (1994), estes comportamentos, captados no tempo veloz, podem ser fatores importantes para o entendimento do processo saúde-doença no que concerne às infecções emergentes. Trata-se de pensar o ser humano dos riscos ("homem dos riscos") de Almeida Filho (1992, p. 144) perambulando por aí, trocando rapidamente de papéis várias vezes.

$\hat{E}$ interessante, neste momento, traçar uma comparação entre os humanos e os microrganismos, os agentes em potencial das infecções emergentes. Nesse sentido, deve ser considerado que as bactérias devem ter surgido há cerca de 3,5 bilhões de anos (Margulis, 1990). Inicialmente unicelulares, provavelmente depois associaram-se biologicamente e inauguraram a vida dos organismos multicelulares no planeta.

Já os seres humanos, como espécie vertebrada Homo sapiens sapiens, têm cerca de duzentos mil anos. Originalmente eram caçadores e coletores, nômades, e depois se agruparam e se tornaram plantadores e criadores de outros animais, se fixando territorialmente. O que, então, deve ter ocorrido há cerca de dez mil anos, configurando a primeira Revolução Agrícola. Neste momento, devem ter oportunizado a circulação de microrganismos e as primeiras epidemias (McKeown, 1982), embora, presumivelmente, as doenças infecciosas já os atingissem há algum tempo, bem como aos outros primatas. Posteriormente, fabricaram ferramentas, meios de locomoção, aprenderam a utilizar os ventos e produziram veículos automotores, máquinas de comunicação e utensilios de guerra para subjugar outros seres humanos, e se lançaram cada vez mais à conquista e colonização de outros territórios.

E continuam, então, sempre por aí, cruzando aceleradamente as "suturas submersas" da antiga Pangéia, a porção única original de terra que se separou nos continentes de hoje, carregando consigo a sua inseparável "biota portátil" repleta de microrga- 
nismos, sua arma mais eficaz no domínio de outros seres humanos e na conquista de novos espaços, tal como o foi na expansão colonizadora européia (Crosby, 1993, pp. 20, 27, 87). Os seres humanos espalharam-se por todos os lugares, como uma "espécie de erva daninha mamífera" (Margulis e Sagan, 1990, p. 213), voraz produtora e consumidora de tecnologias que, na maior parte das vezes, são inúteis ou transcendem suas necessidades básicas.

É curioso estabelecer, então, um raciocínio fundamentado em uma afirmação de James Lovelock (1989), o criador da teoria "Gaia", que apresenta o planeta Terra como um gigantesco organismo vivo, sob uma escala de visualização, portanto, onde os seres humanos seriamos microrganismos. Lovelock (1990, p. 89) admite que, se as bactérias representaram o início da vida na Terra, "a verdadeira função dos mamíferos, incluindo a espécie humana, poderia ser a de se prestar a hábitats ideais para uma certa quantidade de bactérias carregadas nas vísceras". As doenças seriam, assim, muito mais 'paradas' ocasionais necessárias na longa trajetória evolutiva das bactérias do que acidentes de percurso dos humanos.

\section{Finalizando: tempo social e epidemiologia}

Para Sorokin e Merton (1937), em um artigo que se tornou referência constante para a literatura sobre o tema, "tempos sociais" são aqueles marcados por situações significativas para os grupos sociais. São tempos múltiplos, lacunares, marcados por ritmos coletivos específicos e descontínuos, pontuados por festas, rituais, durações de trajetos, durações de operações como o cozimento de determinados alimentos, significações sagradas e laicas, que se prestam, enfim, para a organização da vida social dos grupos.

Em se tratando de sociedades maiores, formadas pela agregação de diversos grupos, estes tempos sociais específicos são inadequados, havendo a necessidade da adoção de sistemas de marcação de tempo de maior alcance, como o tempo-calendário de inspiração astronômica vigente universalmente. O objetivo de tais sistemas de marcação é suprimir as especificidades qualitativas dos diferentes tempos sociais, impondo uma sucessão contínua através da quantificação. No entanto, como explicam Sorokin e Merton (idem), qualquer destes sistemas é contaminado pelos eventos dos tempos sociais. Assim, embora existam os tempos sociais puros, marcados pela descontinuidade dos eventos, no tempo-calendário estes eventos sociais aparecem misturados aos movimentos dos astros e sua numeração.

Já a epidemiologia opera seus conceitos e trabalha seu objeto, "doentes em populações" (Almeida Filho, 1989, pp. 16-7), segundo uma lógica científica positivista e é neste contexto que 
parece se inscrever a perspectiva de tempo que utiliza. Um tempo positivista, que Reis (1994b), ao discutir os tempos da história, descreve como objetivo, descolado da realidade vivida, quantitativo, cujo propósito é superar o potencial de mudança contido no evento, deve ser, portanto, o tempo do conhecimento epidemiológico.

A epidemiologia opera "um corte no tempo" através da análise estatística (Goldberg, 1990, p. 98). Isola e purifica seu objeto e, assim, o amputa de sua historicidade, retira-lhe suas propriedades subjetivas de passado-presente-futuro e lhe impõe condições objetivas, neutras, de anterioridade-simultaneidade-posterioridade. Dessa forma, torna-se difícil para a disciplina perceber a socialização e a historicidade do adoecer coletivo humano. $O$ que, obviamente, se refletirá no modo como a epidemiologia vê as infecções emergentes, ou enxerga sua relação com a aceleração temporal estabelecida pelo capitalismo globalizado.

Nesse sentido, a colocação de duas questões restantes pode configurar uma argumentação final nesta incursão sobre a epidemiologia e o tempo.

Uma das questões mencionadas se refere aos fatores responsáveis pelas infecções emergentes, já descritos. São apresentados pelos citados Lederberg et al. (1992) e Morse (1995) segundo uma taxonomia um tanto estranha, que mais parece querer separá-los uns dos outros do que admitir a sua reunião sob o fenômeno da globalização do capitalismo. Nesta visão fragmentada, onde o marco positivista parece imperar impedindo uma perspectiva que permita perceber processo histórico e conflito, separa-se o comércio do uso da terra, da industrialização, do consumo, do trânsito de pessoas e mercadorias, da eficácia dos serviços de saúde pública, como se na intenção de atribuir a cada um destes fatores valores próprios, isolados, finais em si mesmos.

Uma segunda questão que merece ser considerada diz respeito a uma certa perplexidade que parece envolver os epidemiologistas diante das infecções emergentes. A emergência das infecções no último terço do século XX abala profundamente o crédito no amplamente aceito modelo da transição epidemiológica, baseado na substituição das infecções, que seriam derrotadas fundamentalmente pelos avanços da biomedicina ocidental, pelas doenças não-infecciosas. Tal substituição, de fato, não se deu, e esta constatação gera inquietação em relação aos postulados científicos da epidemiologia.

Estes sentimentos de perplexidade e inquietação transparecem em documentos e relatos resultantes de uma importante e recente oficina de trabalho realizada nos Estados Unidos, em novembro de 1993, sobre o tema disease in evolution - global changes and emergence of infectious diseases. Assim é que nas informações pu- 
blicadas sobre o encontro são abordados pontos como a necessidade da revisão crítica ou do abandono do modelo da transição epidemiológica devido a sua impropriedade (Levins, 1994; Possas e Marques, 1994), a importância das ciências sociais no estudo do adoecer coletivo humano (Wilson; Levins e Spielman, 1994), a inadequação da perspectiva da ciência clássica de domínio e controle da natureza (E. Wilson, 1994), a busca de novos paradigmas e arcabouços conceituais para a epidemiologia (Eckardt, 1994; Levins, 1994; L. Wilson, 1994).

A globalização do capitalismo não pode ser simplesmente descrita e aceita, mas analisada e compreendida em seus reais benefícios e problemas. Desprezar o racismo e a xenofobia e apoiar a miscigenação cultural não requer, de modo algum, eleger a globalização do capital como a forma ideal de aproximação universal, bem como pensar o desenvolvimento científico e tecnológico orientado por princípios éticos sociais e ecológicos, e não pela consecução do lucro a qualquer custo, não significa execrar o progresso humano.

As relações da globalização do capital com o adoecer humano coletivo podem ser observadas no tempo longo da história, quando as epidemias são visualizadas na dialética da duração, emergindo da profundidade pouco conhecida da história, desprendendo-se da lentidão das prisões de longa duração, para usar algumas construções teóricas do historiador francês Fernand Braudel. A apreciação do adoecer humano coletivo nesta perspectiva histórica de um tempo complexo, coletivo e irreversível certamente propicia uma consideração mais adequada dos fatores envolvidos na emergência das infecções e um melhor julgamento do modelo da transição epidemiológica. Além do que, possibilita a formulação de previsões mais adequadas sobre a ocorrência das infecções no contexto das coletividades humanas.

O envolvimento do ponto de vista do tempo na discussão epidemiológica, tratado neste texto, fortalece a inquietação antes mencionada sobre os postulados científicos da disciplina. Evidências apontam a necessidade de a epidemiologia refletir sobre e rever as representações de tempo com que trabalha, conhecer, no âmbito da interdisciplinaridade, outros tempos do conhecimento e compreender melhor os tempos da realidade. Uma realidade complexa, em permanente transformação, onde o histórico, o cultural, o econômico, o político, o social e o biológico se misturam ao adoecer das populações humanas.

Ao nível do conhecimento, esta maneira de perceber a realidade exige também uma nova forma de pensar. Os propósitos da ciência clássica de domínio e conquista da natureza devem ser revistos. As relações entre o ser humano e a natureza devem ser pautadas pelas intenções de convívio e respeito, vistas como oportunidades de trocas de informações e saberes. 
SEVALHO, G.: 'Velocidade/aceleração temporal e infecções emergentes: epidemiologia e tempo social'. História, Ciências, Saüde - Manguinbos, III (2):217-236 jul.-out. 1996.

O texto é uma abordagem sobre epidemiologia e tempo social, tendo como objetivo argumentar sobre a importância do ponto de vista do tempo para a epidemiologia. O tempo é um elemento pouco refletido teoricamente pela disciplina, embora participe de seus conceitos principais. Com a utilização de aportes da história e da geografia, são apresentadas notas históricas sobre o tempo social imposto pelo capitalismo globalizado e suas implicações na saúde das populaçôes humanas. A velocidade/ aceleração temporal das sociedades contemporâneas e suas relações com as infecções emergentes é discutida. Ao final, são desenvolvidas algumas considerações críticas sobre os conceitos de tempo social e um provável tempo epidemiológico.

PALAVRAS-CHAVE: epidemiologia, tempo social, infecções emergentes.

\section{REFERÊNCIAS BIBLIOGRÁFICAS}

Almeida Filho, N. de 1992

Almeida Filho, N. de 1989

Berman, $M$. 1988

Braudel, F. 1992

Braudel, F. 1987

Brudon, P. 1987

Capra, F. 1988

Cárlton, J. T. e Geller, J. B. 1993

Castiel, L. D. 1994

Cipolla, C. M. 1992

Cordeiro, $\mathrm{H}$. 1985

Crosby, A. W. 1993

Dumont, $\mathrm{L}$. 1993

Dupuy, J.-P. e Karsenty, $S$.
A clínica e a epidemiologia. Salvador/Rio de Janeiro, APCE/Abrasco.

Epidemiologia sem números: uma introdução crítica à ciência epidemiológica. Rio de Janeiro, Campus/Abrasco.

Tudo que é sólido desmancha no ar. São Paulo, Companhia das Letras.

'História e ciências sociais. A longa duração'. Em Escritos sobre a história. São Paulo, Perspectiva, pp. 41-78.

A dinâmica do capitalismo. Rio de Janeiro, Rocco.

Medicamentos para todos en el año 2000?. México/Madri/Bogotá, Siglo Veintiuno Editores.

O ponto de mutação. São Paulo, Cultrix.

'Ecological roulette: the global transport of nonindigenous marine organisms'. Science, vol. 261, pp. 78-82.

O buraco e o avestruz: a singularidade do adoecer bumano. Campinas, Papirus.

As máquinas do tempo. Lisboa, Edições 70.

$A$ indústria da saúde no Brasil. Rio de Janeiro, Graal.

Imperialismo ecológico: a expansão biológica da Europa: 900-1900. São Paulo, Companhia das Letras.

O individualismo: uma perspectiva antropológica da ideologia moderna. Rio de Janeiro, Rocco.

A invasão farmacêtutica. Rio de Janeiro, Graal. 
Eckardt, I. 1994

Goldberg, M. 1990

Harvey, D. 1993

Hobsbawm, E. J. 1979

Leach, E. 1961

Lederberg, J.; Shope, R. E. e Oaks, Jr., S. C. (orgs.). 1992

Le Goff, J. 1979

Leroi-Gourhan, A. 1987

Levins, R. 1994

Lovelock, J. E. 1990

Lovelock, J. E. 1989

Margulis, L. 1990

Margulis, L. e Sagan, D. 1990

Mckeown, T. 1982

Morse, S. S. 1995

Nicolas, D. H. 1994

Possas, C. de A. e Marques, M. B. 1994

Reis, J. C. $1994 a$
'Challenging complexity: conceptual issues in an approach to new diseases'. Em M. E. Wilson; R. Levins e A. Spielman (orgs.), Disease in evolution: global changes and emergence of infectious diseases. Annals of The New York Academy of sciences, Nova York, The New York Academy of Sciences, vol. 740, pp. 408-17.

'Este obscuro objeto da epidemiologia'. Em D. C. Costa (org.), Epidemiologia - teoria e objeto. São Paulo, Hucitec/Abrasco, pp. 87-136.

Condição pós-moderna. São Paulo, Edições Loyola.

A era das revoluções. Rio de Janeiro, Paz e Terra.

'Two essays concerning the symbolic representation of time'. Em Rethinking anthropology. Londres, University of London/The Athlone Press, pp. 125-36.

Emerging infections: microbial threats to bealth in the United States. Washington, Institute of Medicine/National Academy Press.

'Na Idade Média: tempo da igreja e tempo do mercador'. Em Para um novo conceito de Idade Média: tempo, trabalho e cultura no Ocidente. Lisboa, Editorial Estampa, pp. 43-60.

O gesto e a palaura - memória e ritmos. Lisboa, Edições 70.

'Basic elements in a conceptual framework for new and resurgent disease: introduction'. Em M. E. Wilson; R. Levins e A. Spielman (orgs.), Disease in evolution: global changes and emergence of infectious diseases. Annals of the New York Academy of Sciences, Nova York, The New York Academy of Sciences, vol. 740, pp. 405-7.

'Gaia - um modelo para a dinâmica planetária e celular'. Em W. I.

Thompson (org.), Gaia - uma teoria do conbecimento.

São Paulo, Editora Gaia, pp. 77-90.

Gaia - um novo olhar sobre a vida na Terra. Lisboa, Edições 70.

'Os primórdios da vida: os micróbios têm prioridade'. Em W. I. Thompson (org.), Gaia - uma teoria do conhecimento. São Paulo, Editora Gaia, pp. 91-101.

Microcosmos - quatro biliôes de anos de evolução bacteriana.

Lisboa, Ediçôes 70.

El papel de la medicina - sueño, espejismo o némesis?.

México, Siglo Veintiuno Editores.

'Factors in the emergence of infectious diseases'.

Emerging Infectious Diseases, (1):11-22.

'Tempo, espaço e apropriação social do território: rumo à fragmentação na mundialização?'. Em M. Santos; M. A. A. de Souza e M. L. Silveira (orgs.), Territorialização, globalização e fragmentação. São Paulo, Hucitec, pp. 85-101.

'Health transitions and complex systems: a challenge to prediction?'. Em M. E. Wilson; R. Levins e A. Spielman (orgs.), Disease in evolution: global changes and emergence of infectious diseases. Annals of the New York Academy of Sciences. Nova York, The New York Academy of Sciences, vol. 740, pp. 285-96.

'Nouvelle bistoire e tempo histórico: a contributição de Febure, Bloch e Braudel. São Paulo, Ática. 
Reis, J. C.

$1994 \mathrm{~b}$

Sabroza, P. C.; Kawa, H. e Campos, W. S. Q 1995

Salem, T. 1991

Santos, M. 1994

Santos, $M$. 1988

Silverman, $M$. e Lee, P. R. 1983

Sorokin, P. e Merton, R. K. 1937

Temporão, J. G. 1986

Virilio, $\mathrm{P}$. 1993

Virilio, P. e

Lotringer, $\mathrm{S}$. 1984

Wilson, M. E. 1994

Wilson, M. E.; Levins, R. e Spielman, A. (orgs.) 1994

Wilson, M. L. 1994

Whitrow, G. J. 1993
Tempo, bistória e evasão. Campinas, Papirus.

'Doenças infecciosas: ainda um desafio'. Em C. Minayo (org.), Os muitos brasis - saúde e população na década de 80. São Paulo/Rio de Janeiro, Hucitec/Abrasco, pp.177-244.

'O individualismo libertârio no imaginário social dos anos 60'. Phisys - Revista de Sañde Coletiva, 1 (2):59-75.

Técnica, espaço, tempo. São Paulo, Hucitec.

Metamorfoses do espaço babitado. São Paulo, Hucitec.

Pildoras, ganancias y politica. México/Madri/Bogotá, Siglo Veintiuno Editores.

'Social time: a methodological and functional analysis'.

The American Journal of Sociology, XIII (5):615-29.

A propaganda de medicamentos no Brasil e o mito da satide. Rio de Janeiro, Graal.

O espaço crítico. Rio de Janeiro, Editora 34.

Gụerra pura: a militarização do cotidiano. São Paulo, Brasiliense.

'Disease in evolution: introduction'. Em M. E. Wilson; R. Levins e A. Spielman (orgs.), Disease in evolution: global changes and emergence of infectious diseases. Annals of the New York Academy of Sciences. Nova York, The New York Academy of Sciences, vol. 740, pp. 1-12.

'Integrating a social sciences perspective into an approach to new disease: introduction'. Em Disease em evolution: global changes and emergency of evolution diseases. Annals of the New York Academy of Sciences.

Nova York, The New York Academy of Sciences, vol. 740, p. 275.

'Developing paradigms to antecipate emerging diseases: transmission cycles and a search for pattern'. Em M. E. Wilson; R. Levins e A. Spielman (orgs.), Disease in evolution: global changes and emergence of infectious diseases. Nova York, The New York Academy of Sciences, pp. 418-21.

O tempo na bistória: concepções do tempo da pré-bistória aos nossos dias. Rio de Janeiro, Jorge Zahar Editor. 